Díaz Gandasegui, V., Elizalde-San Miguel, B. \& Sanz, M.T. Back to the Future: a Sensitivity Analysis to Predict Future Fertility Rates Considering the Influence of Family Policies-The Cases of Spain and Norway. Soc Indic Res 154, 943-968 (2021). https://doi.org/10.1007/s11205-020-02566-7

This is a post-peer-review, pre-copyedit version of an article published in Social Indicators Research. The final authenticated version is available online at: https://doi.org/10.1007/s11205-020-02566-7

\title{
Back to the future: a sensitivity analysis to predict future fertility rates considering the influence of family
} policies. The cases of Spain and Norway. ${ }^{1}$

\begin{abstract}
This article analyzes the relationship between family policies focused on childcare for children under the age of three and fertility levels. In the current context of very low European fertility, it is important to understand whether public support for families can help increase fertility or if, on the contrary, existing fertility levels are the exact reflection of the reproductive desires of families, regardless of the family-support of the policies that may exist in each country. This analysis was carried out through a stochastic dynamic mathematical model that incorporates both demographic variables and family policy variables. A sensitivity analysis was carried out on Spain and Norway, two countries that have very different models of family policies. This sensitivity analysis allows establishing a relationship between the existing family policies and the total fertility rate and also the expected evolution of fertility rates in the future, if the current family policies remain constant. The results showed that the models which lead to an increase in fertility are those which are most generous and which also incorporate a gender perspective, so they allow the identification of good practices and maximum levels of policy efficiency in regards to different objectives such as increase fertility and advances towards gender equality. By contrast, models with erratic and insufficient support clearly contribute to maintaining fertility at very low levels and perpetuate unequal gender relationships. There is, therefore, space for state agency to develop more effective public policies in both dimensions.
\end{abstract}

\section{Keywords}

Family policies; fertility rates; gender equality; work-life balance; mathematical sociology

1 This study was conducted under two competitive research projects: "Ecuaciones en Derivadas Parciales Singulares" (MTM2017-85449-P) and Childcare Practices among Families in Spain: Agents, Practices and Satisfaction (CSO2017-84634-R), funded by the Ministry of Economy, Industry and Competitiveness. It was also supported by the I-Communitas Research Institute - Institute for Advanced Social Research of the Public University of Navarra and the Department of Social Analysis of the Carlos III University of Madrid. 


\section{The study of family policies and fertility}

This article aims to examine the impact that public family policies have on a country's fertility rate. The study of the relationship between these two dimensions has gained relevance in the scope of social sciences in recent decades, considering its implications in areas that constitute an important social concern in the current European environment, such as population ageing or gender equality (Billingsley \& Ferrarini, 2014; Björklund, 2006; D'Addio \& d'Ercole, 2005; Gauthier, 2013; Gauthier \& Philipov, 2008; Hoem, 2008; Kalwij, 2010; Lappegård, 2010; Luci-Greulich \& Thévenon, 2013; McDonald, 2001; Rindfuss, Guilkey, Morgan, \& Kravdal, 2010; Rønsen, 2004; Rønsen \& Skrede, 2010; Thévenon, 2010, Thévenon, 2011).

Usually, fertility is higher in those countries in which female employment rates are highest, childcare provisions are public and universal, there are satisfactory work-life balance mechanisms and both parents are evenly involved in the domestic chores (Castro-Martín and Martín García, 2016; OECD, 2017). To increase the current fertility rates constitutes a socially necessary goal, but only when it contributes to bridging the gap between the number of children that the families desire and those that they end up having. This difference in regards to the ideal family size has remained constant in most European countries for several decades, being specially remarkable in the case of Spain, a country with one of the lowest fertility rates in Europe (Castro, Martín, Cordero \& Seiz, 2020; Beaujouan \& Berghammer, 2019; Sobotka \& Beaujouan, 2014), pointing to social barriers that prevent families from having the number of children they would consider optimal.

This paper contributes to this line of research by developing new tools to understand the relationship between these dimensions. Thus, a mathematical model was designed to explore the current relation between policies and fertility rates, as well as to predict fertility behavior in the future, according to the different family policies that might be implemented. Therefore, the tool presented here aims to facilitate the design of efficient and gendersensitive public policies to increase fertility and it has been applied to two different, Spain and Norway.

The initial hypothesis of this paper is that family policies have a direct influence on fertility, as they are resources that can structurally transform the behaviors and perceptions of citizens and, therefore, families take them into consideration when planning whether or not to have children. Therefore, they can either become barriers or facilitators to reproduction. Indeed, the hypothesis understands that the difficulty of balancing personal and work responsibilities is one of the biggest challenges families currently face, so policies that ease access to more satisfactory work-life balance strategies have a direct impact on both fertility and gender equality. Different models of family policies may also generate different perceptions about the support that the State provides regarding parenthood and childcare; consequently, countries with more generous family policies are those with higher fertility levels and countries with insufficient family policies tend to have lower fertility rates, as citizens perceive that the lack of state support limits the possibility of having children.

According to this hypothesis, we have designed and applied a new mathematical model that calculates the relation of family policies and fertility rates using both demographic variables and family-policies related variables. Indeed, over the last years there has been a significant development of modelling methods that aim to estimate future population trends (Vollset et al., 2020). In this line, the present research has analyzed the impact that different family policies have on fertility rates in Spain and Norway, two countries which were strategically 
selected because they fit within two different models of Welfare State, with diverse understandings of family responsibilities and with dissimilar public resources available for the care of children under the age of three. Thus, the application of the mathematical model to these countries is very useful to test the developed tool and to observe the analysis of the relation of family policies and fertility in distinct contexts. This is, mainly, because in these countries childcare has traditionally been entrusted to two different entities: the state in the case of Norway, and the family in Spain.

Norway has traditionally been classified within the so-called Scandinavian or Nordic Welfare State (EspingAndersen, 1990), with universal public services. This model aims to facilitate work-family reconciliation, promote the well-being of children and move towards gender equality. In this sense, the Norwegian model does not focus purely on pro-natalist policies — which aim simply to increase the number of births — but rather considers the impact of family policies on gender relations and targets gender equality as a socially desirable goal (Brandth and Kvande, 2018). To achieve this goal, the country offers universal childcare services as the most effective mechanism to advance towards gender equality and facilitate work-life balance (Björklund, 2006; Hegewisch \& Gornick, 2011; Kvande, 2009; Lappegård, 2010; Rønsen \& Skrede, 2010). With the application of this model of public support over the last decades, the country has reached one of the highest rates of female employment in Europe (76,8\% in 2019) and also one of the highest fertility rates in the continent in 2009 , when it attained its peak with 1,98 children per women. However, from that moment the fertility rates have experience a slow and gradual decline and, in 2018, its total fertility rate was 1,56, at the same level as the average of Europe (Eurostat, fertility indicators and Labour Force Survey).

Despite being considered one of the countries that have advanced more significantly in regards of gender equality, the Norwegian model still contains controversial elements that limit their efficiency in this area. In this sense, the so called "Scandinavian paradox" refers to the consequences of the principle of 'optionality', which gives families a choice in the childcare strategy they would like to adopt. These alternatives do not always promote father's direct involvement in childcare, leading families to reproduce traditional behaviors by social inertia and maintain the feminization of care (although at lower levels that in other countries). Consequently, this situation provokes or perpetuates gender pay gaps and the segregation of work sectors, which leads women to be the ones who most frequently have to reduce their working hours or work part-time when families have children (Díaz Gandasegui, Díaz Gorfinkiel and Elizalde-San Miguel, 2017; Rostgaard 2014).

Spain illustrates a rather different scenario, with low female employment rates $(62,8 \%$ in 2019$)$ together with low fertility rates (between 1.2 and 1.3 children per woman since the beginning of the $21^{\text {st }}$ century) (Eurostat: fertility indicators and Labour Force Survey). The Spanish case shows that the lowest fertility rates exist in those countries where families, and particularly women, find it harder to balance work and childcare (Gornick \& Meyers, 2008). The low fertility of Spain is not a recent phenomenon, as the country has experienced a continuous decline in this regard from the last decades of the last century, registering what the demographers have call lowest-low fertility rates (Billari y Kohler, 2004). The incidence of this event affects not only the macro elements of the society, but also the micro aspects, as the gap in the aspirations of the families in regards to the number of children desired reflects a well-being deficit (Castro-Martín and Martín García, 2016). Certainly, the desired number of children has remained constant in Spain in the last few decades, with two children as the ideal family size (Sobotka and 
Beaujouan, 2014). Overall data point to a sustained deficit in actual reproduction and the steadily increase on the breach between the ideal family size and the actual fertility rates (Brinton and Lee, 2016; Castro-Martín, and Seiz, 2014). In this regard, recent studies show that Spanish fertility rates are conditioned by the socio-economic position of couples (Bueno \& García Román, 2020), pointing to the existence of institutional and contextual barriers to have children or to the transition from the first child to the subsequent children.

Uncertainty often provokes negative effects on fertility, explaining how the lack of steadiness in family policies in Spain, along with the lack of job stability for women - markedly exacerbated by the economic crisis in recent years - have contributed to create a scenario where women become mothers very late, later than in other countries (32.2 years), and have fewer children (Thévenon and Gauthier, 2011; Spanish National Statistics Institute, 2018). The country is classified within the Mediterranean or Southern Welfare Model (Ferrera, 1996), where private initiatives and family solidarity continue to be —although less than in the past - a fundamental resource in childcare. Thus, since the establishment of democracy, Spain has lacked a clear family policy: the political agenda has been dominated by partial initiatives by different governments that have not facilitated the reconciliation of work and family life. The institutional frame to support work-life balance has been insufficient and the measures adopted have been rhetoric, with abstract commitment and with unsystematic interventions (Castro-Martín, and Seiz, 2014). Indeed, in Spain the public support received by the families is lower than in most European countries and the gap has increased in the last years (Castro-Martín and Martín-García, 2016; Elizalde-San Miguel, Díaz Gandasegui and Sanz García, 2018).

Family policies are structural determinants that, within certain limits, can impact the decision of whether or not to have children, the number of children to have and the moment at which to have them; as Kalwij explains "extending maternity and parental leave and childcare provisions causes women to have children earlier in life and to have more children (2010: 517). However, we must understand that these measures do not operate in a vacuum, as other micro and macro features may influence the number of children that families have. Acknowledging the complexity of the diverse and mutual influences exercised by different dimensions of the society in the fertility decisions, this article applies a mathematical model that incorporates variables from different scopes relative to demographics and public policies.

\section{Methodology}

\subsection{Interdisciplinary methodological approach}

The methodological approach used in this analysis falls within the scope of mathematical sociology and consists in the application of mathematical models and techniques to the field of applied sociology. This is an interdisciplinary approach which aims to improve the effectiveness in the study of public policies, understanding that academic research must provide tools to improve citizens' living conditions. Thus, the mathematical model developed here originally contributes to previous research on the relationship between family policies and fertility with the application of an innovative methodology in which demographic and family-policies related variables are combined, also proposing a sensitivity analysis that allows projecting the future trend in fertility rates. Hence, the application of the model to different countries facilitates to identify best practices, understanding that their potential application to other countries may require their adaptation to the specificities of the diverse contexts. 
An improved stochastic dynamic mathematical model has been applied to analyze the demographic evolution of a country with a diversity of sociological variables, in this case family policies related variables. This mathematical model has been designed as follows:

i) It is based on the von Foerster-McKendrick model, which is widely used for the analysis of agestructured populations and is applied to predict population dynamics by sex and age of a generic human population.

ii) It is also based on the stochastic model designed by Sanz, Díaz Gandasegui and Elizalde-San Miguel (2019). This model includes within the model of von Foerster-McKendrick the Family Policy Index (XFPI) (Elizalde-San Miguel, Díaz Gandasegui \& Sanz, 2018), a composite index that synthesizes into a single figure the main resources and public support that families with children under the age of three receive in each country.

iii) Moreover, the particularity of the model applied in this paper from other demographic models is that it introduces the evolution over time of birth, mortality, immigration and emigration crude rates (Micó, Soler, Sanz, Caselles and Amigó (2019), which allows making projections of the future if changes happen not only at the policy level but also at the demographic level.

Mathematical models, such as the one presented in this paper, are powerful analytical tools with a great potential to examine complex social dimensions and processes thanks to its interdisciplinary design. In this case, the model includes two types of variables ${ }^{2}$ :

a) Demographic variables: births, deaths, emigration and immigration data.

b) Family policies related variables: the model includes variables related to the three types of family policies that — according to the specialized literature - are the most relevant in terms of achieving a satisfactory work-life balance and effective gender equality: educational services, parental leave and monetary transfers (Kammerman \& Kahn, 1994; Tobío \& Fernandez-Cordón, 2005).

The objective of the model presented in this paper is, in short, to analyze which policies are most impactful to increase fertility and identify the key elements to ensure their effectiveness, based on the premise that efficiency must combine both the influence on fertility and on gender equality.

To achieve this goal the stochastic model for the present period (2008-2017) has been validated, ensuring that the outcome of the model fit with the real data. Then, the model has been extrapolated to a future period (2018-2035), predicting the potential demographic scenario if current conditions are maintained. With the results obtained, a sensitivity analysis - a technique that allows establishing whether there is a causal relationship between variables — has been performed to explore the relationship between the Total Fertility Rate $(X T F R)$ and the Family Policy Index $(X F P I)$. The sensitivity analysis also calculates the relationship between the Total Fertility Rate and some specific family policies (parental leave for fathers, coverage of public pre-school services and coverage of "child benefits"). Hence, the sensitivity analysis was applied to the historical values available in the existing databases (see sources in Annex I) and to the predicted values for the future trend generated by the model (in the

${ }^{2}$ The list of variables included in the model is available in Annex 1 
event that there are no substantial changes in public policies) ${ }^{3}$.

\subsection{Introducing XFPI in a Demographic Model}

The socio-demographic model defined by age and sex presented below (1), (2) \& (3) takes its initial structure from the von Foerster-McKendrick model for population dynamics (Micó, Caselles, Soler, Sanz \& Martínez, 2008) and it includes the modifications made by Micó, Soler, Sanz, Caselles and Amigó (2019). Therefore, it introduces in the model the evolution of immigration, emigration, birth and mortality crude rates and also the $X F P I$, calculating the specific fertility rates by age of the mother and defined by sex of the child born.

$$
\begin{aligned}
& \frac{\partial w_{i}(t, x)}{\partial t}+c \frac{\partial w_{i}(t, x)}{\partial x}=\left(\left(-\bar{d}_{l}(x) \cdot \frac{d_{i}(t)}{d_{1}(t)+d_{2}(t)} \cdot \operatorname{deat}(t)+\bar{f}_{l}(x) \cdot \frac{y_{i}(t)}{y_{1}(t)+y_{2}(t)} \cdot \operatorname{inmi}(t)-\bar{g}_{l}(x) \cdot \frac{e_{i}(t)}{e_{1}(t)+e_{2}(t)}\right.\right. \\
& \left.\operatorname{emig}(t)) \cdot \int_{0}^{+\infty}\left(w_{1}(t, x)+w_{2}(t, x)\right) d x \cdot w_{i}(t, x)\right) \\
& w_{i}(t, 0)=\operatorname{birt}(t) \cdot \frac{b_{i}(t)}{b_{1}(t)+b_{2}(t)} \cdot \int_{0}^{+\infty}\left(w_{1}(t, x)+w_{2}(t, x)\right) d x \cdot \int_{0}^{+\infty} \bar{b}_{l}(x) \cdot w_{2}(t, x) d x \\
& w_{i}\left(t_{0}, x\right)=u_{i}(x)
\end{aligned}
$$

Where $i=1$ represents men and $i=2$ represents women.

Equation 1 comes from von Foerster-McKendrick and determines the evolution of population based on specific mortality rates (4), specific immigration rates (5) and specific emigration rates (6) by age and sex:

- $\quad$ Specific mortality rate by age and sex

$$
\left(-\bar{d}_{i}(x) \cdot \frac{d_{i}(t)}{d_{1}(t)+d_{2}(t)} \cdot \operatorname{deat}(t)\right),
$$

- Specific immigration rate by age and sex

$$
\left(\bar{f}_{i}(x) \cdot \frac{y_{i}(t)}{y_{1}(t)+y_{2}(t)} \cdot \operatorname{inmi}(t)\right) \text {, }
$$

- Specific emigration rate by age and sex

$$
\left(-\bar{g}_{i}(x) \cdot \frac{e_{i}(t)}{e_{1}(t)+e_{2}(t)} \cdot \operatorname{emig}(t)\right) \text {. }
$$

Equation (2) represents the boundary condition, that is, the population aged $0, \mathrm{x}=0$, which is equivalent to births.

Equation (3) is the initial condition, that is, population density at the beginning of the period $\left(t=t_{0}\right), u_{i}(x)$ or the

\footnotetext{
${ }^{3}$ To observe the actual effect of each input variable on the given output variable, we must consider that the other input variables are constant or we must take a random sample of all possible combined values. Otherwise, as in the present case, the analysis will be valid only for the specific situation examined. An example of this approach is explained in Caselles et al. (1999).
} 
population distribution by age in the initial year.

As explained above, the innovative feature of this model is that it introduces birth $(\operatorname{birt}(t))$, mortality $(\operatorname{deat}(t))$, immigration and emigration (inmi $(t)$, emig $(t))$ crude rates, allowing to make projections for the future. To do so, specific rates mentioned in equations (2), (4), (5) and (6) have been calculated as follows:

i) Firstly, it includes the proportion of births, deaths, immigration and emigration, by sex $\left(\frac{b_{i}(t)}{b_{1}(t)+b_{2}(t)}, \frac{d_{i}(t)}{d_{1}(t)+d_{2}(t)}, \frac{y_{i}(t)}{y_{1}(t)+y_{2}(t)}, \frac{e_{i}(t)}{e_{1}(t)+e_{2}(t)}, \quad\right.$ respectively) where, $b_{i}(t), d_{i}(t), y_{i}(t)$ y $e_{i}(t)$ corresponds to births, deaths, immigrants and emigrants by sex and year.

ii) On the other hand, it has been introduced $\bar{b}_{i}(x), \bar{d}_{i}(x), \bar{f}_{i}(x)$ and $\bar{g}_{i}(x)$ that are calculated as the ratios between the four age and sex-specific rates and births, deaths, immigrants and emigrants in $t=0$.

iii) Finally, for the equations to be consistent, this is multiplied by the total population of both sexes and temporarily defined through $\int_{0}^{+\infty}\left(w_{1}(t, x)+w_{2}(t, x)\right) d x$.

Following Sanz, Díaz Gandasegui and Elizalde-San Miguel (2019) the Family Policy Index (XFPI) has been introduced into the model, with the fertility rates defined by the mother's age and sex of the newborn. With that, (2) is transformed by (7),

$w_{i}(t, 0)=\operatorname{birt}(t) \cdot \frac{b_{i}(t)}{b_{1}(t)+b_{2}(t)} \cdot \int_{0}^{+\infty}\left(w_{1}(t, x)+w_{2}(t, x)\right) d x \cdot \int_{0}^{+\infty} \bar{b}_{l}(x, X F P I(t)) \cdot w_{2}(t, x) d x$

\subsection{Variables used and variable adjustment procedure}

Historical data on the input and demographic variables of the model were obtained from Eurostat for the period 2007-2017, as well as from the corresponding national legislation.

The adjustments of the historical data of the mentioned variables of each country to the mathematical structures that have been defined were carried out through the Mathematica 11.00 (Wolfram, 2017) using the NonLinearModelFit package and with the fitter function Regint (Caselles, 1998, 2008).

The variables that can be fitted over time are those which have, in the past, undergone modifications and which have a tendency that can be approximated by a function or combination of mathematical functions. Within the scope of the family policies analyzed, the changes represent the intentionality of each country in regards to childcare. For example, the fact that a country is increasing the public coverage of places in pre-school services implies that there is recognition from the state that this is a necessary resource for citizens in order to produce a more satisfactory work-life balance and to promote gender equality. From this point of view, the variable "coverage of places for early childhood education for 0-3-year-olds" has undergone relevant modifications in the past in both countries, allowing two types of analysis: a) from a mathematical perspective it enables to model the behavior of this variable, identifying the past trend and predicting how it will evolve in the future if the intentionality of the State regarding this policy remains constant; b) from a sociological perspective, it explains the political intentionality, analyzing this situation from different points of view (gender equality, work-family 
balance, impact on fertility, children's educational rights, etc.).

On the other hand, the variables that have remained constant in the past can be analyzed from a sociological viewpoint, but cannot be mathematically 'modeled', as their temporal behavior cannot be adjusted. This is the case, for example, of maternity leave in Spain. This policy has remained constant at 112 days (16 weeks) during the entire period analyzed (2008-2017). Therefore, these variables cannot be adjusted through a function defined by time, and will enter the model through discrete values for each year. For this reason, the fitted variables do not need to be the same in each country, since the model introduces the values for each country independently.

Henceforth, the variables available to be fit and evaluated in regards to the target variable of fertility $(X T F R)$ are:

- In Spain: parental leave corresponding to the father $(D F A L)$, public coverage of pre-school places for 03-year-olds (XPUB), the coverage of the economic transfer known as "child benefit" - the number of people (women, in the case of Spain) who receive this type of financial transfer $(X C C B)$.

- In Norway: paternity leave $(D F A L)$, maternity leave $(D M A L)$ and public coverage of pre-school places for 0-3-year-olds $(X P U B)$.

\section{Results}

\subsection{Model Validation}

The results of the numerical validation of the model are presented below following its deterministic formulation. For this purpose, the determination coefficients and randomness of residuals have been calculated. In addition, the trends of the historical and simulated periods have been included, observing whether overlap for each year occurs or whether the difference is small. The model will be validated when high determination coefficients are met, as well as with maximum relative errors of $5 \%$.

The software used for validation was SIGEM (Caselles, 1998, 2008). The model was designed as a set of differential and functional equations. The solutions were calculated with the Euler Method, following Djidjeli, Price, Temarel \& Twizell (1998), who consider Euler's Method as the most appropriate to solve such equations. This approach results in a set of finite differential equations that were programmed in Visual Basic 6.0 and executed using SIGEM.

This validation section includes a selection of output variables ${ }^{4}$ : the demographic variables of births, deaths and migratory movements in Spain for women (see Fig. 1). Output variables are contrasted with historical data, emphasizing the validation of the model presented in this paper.

Fig. 1. Validation of the model in its deterministic formulation for women in Spain: a) births $\left(R^{2}=0.80647\right)$, b) deaths $\left(\mathrm{R}^{2}=0.77285\right)$, c) emigrations $\left(\mathrm{R}^{2}=0.55675\right)$ and $\left.\mathrm{d}\right)$ immigration $\left(\mathrm{R}^{2}=0.90765\right)$. Points: historical values, line: simulated values.

\footnotetext{
${ }^{4}$ The model was validated for all the variables, applying the methodology followed by Sanz, Díaz Gandasegui and Elizalde-San Miguel (2019)
} 


\section{a) < INSERT FIGURE 1A ABOUT HERE > b) < INSERT FIGURE 1B ABOUT HERE > \\ c) $<$ INSERT FIGURE 1C ABOUT HERE $>$ d) < INSERT FIGURE 1D ABOUT HERE $>$}

Source: own elaboration

The validation of the model was considered successful according to three different reasons: i) the graphic representation of the overlap between actual and estimated values; ii) a high determination coefficient; iii) a maximum relative error below $5 \%$.

\subsection{Sensitivity analysis applied to Spain}

Fig. 2a reflects the relationship between fertility and paternal leave in Spain during the 2007-2017 period. It is important to mention that during those years paternal leave was very short, with significant differences with the maternal leave, although it did increase from 2 to 15 days. The figure shows a quadratic relationship between both variables, pointing to an increase in fertility (up to 1.45 children per woman) when the duration of the paternal leave was extended. Despite this positive modification, fertility remained quite low in Spain, especially considering the so-called generational replacement index, which is estimated at 2.1 children per woman.

Fig. 2 Relationship between fertility $(X T F R)$ and paternal leave $(D F A L)$. a) Past, quadratic relation, $\mathrm{R}^{2}=0.356993$ (points $=$ real data; line $=$ fitted quadratic function). $b$ ) Future, quadratic relation, $\mathrm{R}^{2}=0.834325$ (points $=$ simulated data; line $=$ fitted quadratic function).

\section{a) $<$ INSERT FIGURE 2A ABOUT HERE $>$ \\ b) $<$ INSERT FIGURE 2B ABOUT HERE $>$}

Source: own elaboration

As can be observed in Figure 2b, the slow growth of the paternity parental leave in the past period allows to foresee a stagnation of this policy in the future, which would contribute to a continued decline in fertility. However, it is important to take into consideration that modifications of the paternal leave have recently been approved, and since $1^{\text {st }}$ of January 2020 the leave has increased to 12 weeks, with an expected extension to the 16 weeks that mothers currently receive in 2021; nevertheless, these alterations have taken place after the period analyzed in this article. Certainly, as these modifications in the paternal leave are not coherent with the alterations in the rest of the family policies, it can be foreseen that the impact on fertility will be low, since positive effects occurs when there is consistency between different public policies and resources offered. Despite this limitation, the modification of this policy constitutes a breakthrough in terms of recognizing fathers as caregivers for their children. Also, the experiences of other countries show that the implementation of lengthy paternal leave combined with the model of "fathering alone" (exclusively for fathers, non-transferable and not simultaneous to the leave of the mother) generates a greater involvement of fathers in the care of children in the long term. Therefore, the recent increase of the paternal leave in Spain may have a very limited impact in terms of increasing fertility if it is not combined with other measures, but it may contribute significantly to advance towards gender 
equality.

Fig.3 Relationship between fertility $(X T F R)$ and coverage of public pre-school services for 0 to 3 year-olds $(X P U B)$. a) Past, quadratic relation, $\mathrm{R}^{2}=0.87505$ (points = real data; line = fitted quadratic function). b) Future, quadratic relation, $\mathrm{R}^{2}=0.995503$ (points $=$ simulated data; line $=$ fitted quadratic function).
a) $<$ INSERT FIGURE 3A ABOUT HERE $>$
b) $<$ INSERT FIGURE 3B ABOUT HERE $>$

Source: own elaboration

Pre-school public educational services $(X P U B)$ are considered the family policy that most effectively contributes to family reconciliation, gender equality and social cohesion, since they allow women to actively participate in the labor market by guaranteeing the care of children (Campillo Poza, 2010; Korpi, 2000; Rindfuss, Guilkey, Morgan, Kravdal \& Guzzo, 2007; Thévenon \& Gauthier, 2011). The pre-school services facilitates the defamiliarzation of care and eases the conflict traditionally faced by women between work and care, hence they also contribute to increase fertility by reducing the opportunity cost of having children, especially when the mother works (Baizán, 2009; Baizán, Arpino and Delclós, 2016). The sensitivity analysis applied to public pre-school educational services and fertility shows a quadratic relationship $\left(\mathrm{R}^{2}=0.87505\right)$ in the 2007-2017 period (Fig. 3a). During the first years of this interval the coverage of pre-school places raised by $300 \%$ and the fertility increased from the historical lows reached in 1998 (1.13 children per woman) to values of 1.45 children per women, confirming the positive relationship between these variables, which has previously been observed in other countries (Thévenon \& Gauthier, 2011; D'Addio \& d'Ercole, 2005). However, once those maximum values were achieved, and possibly coinciding with the cancellation of the Educa3 plan, which was intended to significantly increase preschool educational services, the fertility trend experienced again a decline. Hence, the investment in pre-school places only showed an impact on fertility up to a certain level, but has been proved insufficient to get Spain out of the group of countries with the lowest fertility in Europe.

Nonetheless, to understand this quadratic relationship it should be noted that the increase of $300 \%$, despite being significant, remained unsatisfactory. Certainly, the public coverage offered by the public pre-school educational system in Spain in recent years has not exceeded 20\% for the population aged 0 to 3 years. Consequently, as the resources offered does not guarantee a place to all the children, this has direct implications in the decision of whether or not to have children. Also, this means that some families have to find alternative childcare solutions 
when public pre-schools services are unavailable, such as using private resources (hiring caregivers or private schools) or traditional strategies, primarily based on family and female care, revisiting - probably with less intensity than in the past - the Mediterranean familialism, which led to a situation of gender inequality and intergenerational solidarity that is not easily sustainable in the present.

The future fertility scenario (Fig. 3b), if the current design of public policies is maintained, expose that public places will continue to increase at a very low rate (only 4000 places until 2035) and, consequently, this will not contribute to modify the continued decline in fertility. The expected scenario demonstrate that until the coverage of public pre-school places do not approach the targeted population (that is, until there is universal coverage or there are clear advances in this regard), fertility will continue to be very low and will even fall from its current rates (Sanz, Díaz Gandasegui and Elizalde-San Miguel, 2019).

Fig. 4 Relationship between fertility $(X T F R)$ and child benefit coverage $(X C C B)$. a) Past, linear relation, $\mathrm{R}^{2}=0.756038$ (points $=$ real data; line $=$ fitted linear function). b) Future, quadratic relation, $\mathrm{R}^{2}=0.999814$ (points $=$ simulated data; line $=$ fitted quadratic function).

\section{a) $<$ INSERT FIGURE 4A ABOUT HERE $>$ \\ b) $<$ INSERT FIGURE 4B ABOUT HERE $>$}

Source: own elaboration

Fig. 4 reflects the relationship between fertility and the child benefit coverage $(X C C B)$, a monetary transfer of 100 euros per month to working mothers until the children turns three years old. Monetary transfers tends to have positive effects on fertility; frequently its major impact is on the moment at which parents decide to have children (D'Addio \& D'Ercole, 2005; Thévenon \& Gauthier, 2011; Castro-Martín, Martín-García, Cordero, \& Seiz (2018), but its effectiveness to facilitate a satisfactory work-life balance is reduced compared to other measures (Salles, Rossier \& Brachet, 2010).

The child benefit coverage was implemented with the intention of softening the cost of caring for children in the early stages of their lives and is implicitly intended to encourage fertility. The child benefit in Spain is not universal, as it is subject to the mother's employment status, implying a specific intentionality in the way in which this family policy was designed: it is not a right of the child, but rather of the mother, which is also indicative of a vision of parenting that has a clear gender bias. However, this policy has been justified in Spain as a stimulus to female employment, understanding that female participation in the labor market must be promoted and should not be perceived as a barrier to having children.

The relationship between fertility and $X C C B$ differs from the two previously analyzed policies (DFAL and XPUB). As Figure 4a reflects, the relationship between fertility and female employment in the past period is positive and linear, similar to the association observed in many other countries (Lappegård, 2010; Thevenon, 2011), confirming that female employment, far from being an obstacle to fertility, is an incentive to rise it. The promotion of female participation in the labour market may facilitate social and demographic transformations: firstly, in the short term, it increases fertility rates when women find job stability and families have sufficient economic resources to have 
children. Secondly, in the long term, fertility rises when like in a game of dominoes one piece can alter the whole set of pieces, provoking modifications in the macro level: in gender relations and in the social and economic organization. In both cases, short and long modifications, family policies are able to alter the existing gender balance by transforming social and cultural behaviours, expectations and constrains.

The simulated future trend (Fig. 4b) shows that female employment will continue to grow (since we can observe that Child Benefit coverage will continue to increase in the coming years), and also demonstrates that fertility will not start to increase in Spain until female employment reaches $80 \%$, a result that is consistent with what has been observed in other countries. Low levels of female employment clearly constitute a disincentive for fertility, as families perceive that they do not have enough economic resources to care for their families.

Fig. 5 Relationship between fertility $(X T F R)$ and the Family Policy Index $(X F P I)$. a) Past, quadratic relation, $\mathrm{R}^{2}=0.644663$ (points = real data; line = fitted quadratic function); b) Future, linear relation, $\mathrm{R}^{2}=0.999457$ (points $=$ simulated data; line $=$ fitted linear function).

\section{a) < INSERT FIGURE 5A ABOUT HERE > \\ b) $<$ INSERT FIGURE 5B ABOUT HERE $>$}

Source: own elaboration

Once the direct relationship between specific policies and fertility levels has been analyzed, it is relevant to understand the global impact of family policies in the fertility of the country, since policies do not normally operate in isolation or independently, but rather in conjunction with other policies, configuring a scenario in which families base their decision on whether or not to have children. In this sense, the Family Policy Index (XFPI), which shows the total support a country offers through its family policies (measured in a range between 0 and 1 ) has been included in the analysis (figure 5a). It is important to point out that in the interval analyzed (2007-2017), public support grew steadily, but these increases were very limited, with XFPI barely reaching 0.2 (Elizalde-San Miguel, Díaz Gandasegui y Sanz García, 2018). Hence, the observed quadratic relationship, consistent with the previous analysis of the different policies, indicates that the constant but limited growth in the investment of family policies had a positive impact on fertility, but only up to a certain point (1.45 children per woman), the point at which the policies lose their ability further enhance fertility, and consequently it falls again.

Fertility trends are usually related to the economic cycle of a country and, in the Spanish case, the quadratic relationship between fertility and family policies also requires a complementary clarification. Family policies in Spain have been recent, with a clear delay comparing them to other European countries. It was not until the first decade of the 21 st century that these policies began to take off, due, above all, to recommendations made by the European Union (regarding, for example, the provision of pre-educational services). In addition, the economic bonanza experienced by Spain in those decades facilitated that families decided to have children. Also, the arrival of a considerable amount of foreign migrant population provoked a significant increase in fertility during a relatively short period, as this group was characterized by a young age structure and showed higher fertility rates than the Spanish population (Castro-Martín and Martín-García, 2013). However, the migrant population 
experienced a rapid adaptation to the cultural conditions and fertility rates of the native population, producing only a temporary boost effect in the national fertility rates (Del Rey Poveda and Ortega Osonio, 2011; Devolder and Bueno, 2011).

Therefore, the quadratic relationship observed was influenced by a moment of economic growth, but the favorable situation was not used to implement a generous and universal family policy model which could have had a determining effect on fertility rates that were, despite their increase, at a very low level. Consequently, the capability of the Spanish family policy model to increase fertility proved to be very limited, as can be observed in the decline in fertility in the final part of the period, when the incidence of migration on fertility was attenuated. Here, the insufficient provision of resources together with other contextual elements, such as the economic upheaval, the increased unemployment or the assimilation of fertility behaviours of the immigrants to the Spanish population, might have interacted, reducing the fertility rates (Castro-Martín and Martín-García, 2013).

The analysis of the future behavior of XFPI (Fig. 5b) warns of an important stagnation of family policies in the years to come (until the year 2023), since the index will experience a minimal increase, going from 0.2 to 0.23 (over a total value of one). Therefore, the expected evolution of this index reflects that the Spanish family policy model is stationary and if there are no significant changes in the set of family policies offered, these will discourage families from deciding to have children, decreasing the present fertility rates, which are already at very low levels.

\subsection{Sensitivity analysis of Norway}

The relationship between family policies and fertility in Norway over the last decade has been characterized by higher fertility rates than those in Spain (between 1,98 and 1,5 children per woman), with generous and universal family policies, which have been consolidated with a social and political consensus to achieve a satisfactory workfamily reconciliation and gender equality.

Fig. 6 Relationship between fertility $(X T F R)$ and parental leave $(D F A L)$. a) Past, quadratic relation, $\mathrm{R}^{2}=0.0272921$ (points $=$ real data; line $=$ fitted quadratic function); b) Future, linear relation, $R^{2}=0.271181$ (points $=$ simulated data; line $=$ fitted linear function).
a) $<$ INSERT FIGURE 6A ABOUT HERE $>$
b) $<$ INSERT FIGURE 6B ABOUT HERE $>$

Source: own elaboration

Fig. 7 Relationship between fertility $(X T F R)$ and maternal leave $(D M A L)$. a) Past, quadratic relation, $\mathrm{R}^{2}=0.42155$ (points $=$ real data; line $=$ fitted quadratic function); b) Future, linear relation, $\mathrm{R}^{2}=0.937769$ (points $=$ simulated data; line $=$ fitted linear function).

a) < INSERT FIGURE 7A ABOUT HERE >

b) < INSERT FIGURE 7B ABOUT HERE > 
Source: own elaboration

In regards to parental leave (Fig. 6 and 7), the analysis of both the past period and the future period shows that when the parental leave approaches 70 days for each parent (a total of 140 days of joint leave) the maximum level of fertility, at around 1.9 children per woman, is attained. Certainly, this is one of the highest fertility rates in developed countries and, consequently, it cannot be expected much higher fertility rates.

Increasing parental leave over those 70 days per parent should be understood, in this sense, as an objective that goes beyond pro-natalist goals and it rather targets to improve family welfare. Thus, in addition to allowing children to be cared for directly by their parents during their first weeks or months of life, the design of long and equally distributed parental leaves facilitates gender equality, reducing the obstacles that mothers face in regards to rejoining the labor market after motherhood and also aids to balance home and caring responsibilities.

Fig. 8 Relationship between fertility $(X T F R)$ and coverage of public pre-school services $(X P U B)$. a) Past, quadratic relation, $\mathrm{R}^{2}=0.0553027$ (points = real data; line = fitted quadratic function); b) Future, linear relation, $\mathrm{R}^{2}=0.65022$ (points $=$ simulated data; line $=$ fitted linear function).

\section{a) $<$ INSERT FIGURE 8A ABOUT HERE $>$ \\ b) $<$ INSERT FIGURE 8 B ABOUT HERE $>$}

Source: own elaboration

Norwegian public pre-school services have guaranteed, since 2009, a place for all children over the age of one, producing a positive impact on fertility. However, fertility rates started to decrease once the coverage reached $80 \%$ of the total population $0-3$ as can be observed in figure. 8a. From that point this resource is not able to increase fertility independently and, consequently, the slight rise that occurs in the future period may be caused by the interrelation with other policies and services offered.

In the future (Fig. 8b), a small increment in places in pre-school education, that is, continuing to offer universal care services, will allow a maintenance (or even a small increase) of the fertility, being Norway at very high levels within the European context. Also, as it was previously mentioned, this service constitutes a fundamental tool in terms of easing family reconciliation, the incorporation of women into the labor market and generating social cohesion (Eydal and Roostgaard 2011).

In short, the two policies observed in Norway (parental leave and coverage of educational services) have followed a consistent and similar pattern. Firstly, these policies were able to stimulate the growth of fertility and later, when the universality of services was guaranteed and parental leave was considered generous and sufficient by the families, fertility declined slightly, although it remained at levels that are high compared to other developed countries. However, the trend shown by the package of family policies (Fig. 9a) indicates that the investment in a sophisticated and extensive family policy system has a positive influence on fertility, reaching figures that approximate the number of children per woman to the number of children families desire to have. The forecast shown by the mathematical model revealed very high fertility rates (Fig. 9b); indeed, they may be excessive 
according to the reproductive preferences of the families and particularly of women. However, the contribution of the model designed is to identify a trend that indicates that the family policies developed in recent decades encourage high levels of fertility as they meet the demands of the families when they consider having children.

Fig. 9 Relationship between fertility $(X T F R)$ and the Family Policy Index $(X F P I)$. a) Past, quadratic relation, $\mathrm{R}^{2}=0.346609$ (points = real data; line = fitted quadratic function); b) future, linear relation, $\mathrm{R}^{2}=0.187498$ (points $=$ simulated data; line $=$ fitted linear function $)$.

a) $<$ INSERT FIGURE 9A ABOUT HERE $>$

b) $<$ INSERT FIGURE 9B ABOUT HERE $>$

Source: own elaboration

The sensitivity analysis of the future period regarding the combined results of all the policies (XFPI) and their relationship with fertility yield different outcomes to the forecasts based on each family policy in isolation, indicating that if the package of family policies maintain their current trend, the fertility will decrease slightly, although it will continue to be at high levels, considerably higher than in Spain.

The current design of family policies in this country has the potential to maintain (with small variations) the previous fertility levels, foreseeing a high degree of political stability and civil consensus. Even if fertility is not increased by the impact of family policies, understanding that they have achieved a satisfactory degree, their development may further facilitate the well-being of families. It is in this area where family policies still have a clear margin for improvement. In fact, the XFPI reaches in the analyzed period a value of 0.7 and the future forecast is that it will remain at similar figures $(0.75)$, reflecting that the country is currently, and will remain in the future, far from achieving the ideal of gender equality in the design of its family policies (Elizalde-San Miguel, Díaz Gandasegui and Díaz Gorfinkiel, 2019).

\section{Conclusions}

The initial hypothesis of this research was that family policies have a direct influence on fertility as they are resources that families take into consideration when planning whether or not to have children. The result of this investigation partially accepts this hypothesis, as it has been found that family policies produce an impact on fertility to a certain degree. However, certain factors may affect the relationship between family policies and fertility: firstly, the micro and macro elements that shape the culture, traditions and behaviours of the individuals and populations. In this sense, it has been recognized by this investigation that family policies are able to modify the current structures but are also a consequence of the constrains exercised by the same structures and thus, in a feedback process, produce peculiar social dynamics. In other words, and in the line of the ideas of Max Weber, the influence of the family polices on fertility should be understood in its context. Hence, the configuration of the 
policies and the repercussion in the population depend on several factors which are inherent to the culture, habits and traditions of the society. Secondly, the effect of family policies in fertility is also contingent on other conjunctural factors, such as economic upheavals or migration flows, which are not identified by the mathematical models. Nonetheless, the interdisciplinary nature of this research allows combining the relation among different variables with the sociological interpretation of the phenomena analyzed.

The examination of the relationship between fertility and family policies is highly complex and requires extensive knowledge about the scenario in which the public policies are being applied: the demography, cultural background and existing gender inequalities. As it has been recently noted, the interest in undertaking ambitious comparisons across diverse countries may oversimplify the outcomes of "complex phenomena, such as migration theory and policy" (Gletel-Basten \& Sobotka, 2020). Indeed, the results obtained for Spain and Norway should not simply be analyzed as a direct comparison between these two strategically selected countries, but rather as two different models that lead to diverse fertility scenarios from which best practices and lessons learned can be identified.

From this perspective, the transfer of strategies from one country to another is not always possible, as well as the identification of desirable levels of investment to promote fertility. A simplistic and hasty interpretation of the relationship of family policies and fertility could lead to the conclusion, for example, that parental leaves in Norway should be, at most, 70 days, as this is the point at which fertility begins to decline. However, this analysis would ignore that this measure aids to generate a more equal distribution of the parental leaves, contributing to gender equality and eroding the barriers that women face in their incorporation and maintenance in the labour market. Similarly, a deceived interpretation of the public investment in family policies (XFPI) in Spain could lead to deduce that their expansion would not produce an increase in the fertility rates. Nonetheless, this analysis would ignore that the entire package of family policies in Spain is currently insufficient, as the XFPI values demonstrate, and with such a small investment in family measures and services the fertility will continue to decline.

Also, sometimes family policies do not produce concrete or short-term effects on fertility; however, they usually send signals to the citizens and shape cultural behaviours about the responsibility assumed by the state and the families towards childcare. Furthermore, the implementation of family policies requires the generation of a social and political culture which serves as a breeding ground in which converge specific measures with the demands and needs of the population (Salles, Rossier \& Brachet, 2010; Hoem, 2008; Thévenon \& Gauthier, 2011). In Norway, the consensus about the measures directed towards universal coverage of pre-school services and the extension of parental leaves meant that citizens responded earlier to these proposals by increasing fertility rates and closing the gap between the number of children that families actually have and the number of children they desire. However, the recent decline of Norwegian fertility rates opens the debate about the limits of their public policies, focusing on the "optionality" of their care policies, as this characteristic is not gender neutral and maintains the so-call Scandinavian paradox. In Spain the economic crisis and the corresponding cuts in resources and services meant an alteration in the previous trend in family policies (León \& Pavolini, 2014). Families adapted their fertility decisions, very often postponing the moment of having children, in a context in which the uncertainty in the labor market was combined with disincentives from public resources and services regarding childcare, precisely at a time when families demanded more support than in previous periods.

Therefore, it is essential that family policies are consistent and sustained over time and that citizens perceive them 
as structural provision and not short-term policies. Disconnected policies to support families, as has been observed in the case of Spain, often lead to gender inequalities that discourage fertility. On the other hand, as we can observe in Norway, policies that are coherent in their goals and orientation facilitate work and family reconciliation and reduce the obstacles perceived by citizens when they consider having children. Therefore, in the current scenario of very low fertility and the challenges related to population ageing, family policies must constitute a clear priority for policy makers to ensure that fertility rates do not continue falling below the ideal family size desired by the families.

The application of mathematical models to the field of sociology has considerable potential to examine complex social phenomena. The modeling of social behaviors is a risky endeavor, as they are not always strictly replicable and are subject to changes in trends that mathematical models are not always able to anticipate, as has happened with the recent increase in paternal leave in Spain. In spite of this, the methodology used in this paper contributes to the social knowledge by examining specific social dynamics from a different perspective, allowing the generation of recommendations to move towards a more effective public policy model that incorporates concrete objectives, such as gender equality or the equalization of desired and real fertility, the two main points analyzed in the present paper.

Henceforth, the goal of this paper has been to shed light into the relation of family policies and fertility in two different countries with different context and diverse Welfare State models. However, the present research has certain limitations that also constitute future proposals. In this regard, the strategic selection of two countries with different traditions and behaviors in the area of family polices only permits to examine two different scenarios with all the peculiarities attached to them. Hence, the future intention is to extend the study of the relation of family policies and fertility in different countries and Welfare State Models. Secondly, even if the study of concrete family policies in both countries has allowed to obtain very significant interpretations about the relation of specific measures and their effect of the fertility rates, it would be interesting to expand the number of policies and demographic variables applied to the model to attain a more detailed picture of the relationship of the family policies and the fertility rates, both holistically and individually.

\section{References}

Baizán, P. (2009). Regional child care availability and fertility decisions in Spain. Demographic research, 21, 803-842.

Baizán, P., Arpino, B., \& Delclós, C. E. (2016). The effect of gender policies on fertility: The moderating role of education and normative context. European Journal of Population, 32(1), 1-30.

Beaujouan, E., \& Berghammer, C. (2019). The Gap Between Lifetime Fertility Intentions and Completed Fertility in Europe and the United States: A Cohort Approach. Population Research and Policy Review, 38, 507535.

Billari, F., \& Kohler, H. P. (2004). Patterns of low and lowest-low fertility in Europe. Population studies, 58(2), 161-176.

Billingsley, S., \& Ferrarini, T. (2014). Family policy and fertility intentions in 21 European countries. Journal of Marriage and Family, 76(2), 428-445. doi:10.1111/jomf.2014.76.issue-2 
Björklund, A. (2006). Does family policy affect fertility? Journal of Population Economics, 19(1), 3-24. doi:10.1007/ s00148-005-0024-0

Brandth, B., Kvande, E. (2018). Enabling or promoting gender equality through parental leave policies. Revista Española de Sociología, 27, 107-120. doi: http://dx.doi.org/10.22325/fes/res.2018.36

Brinton, M. C., \& Lee, D. J. (2016). Gender-role ideology, labor market institutions, and post-industrial fertility. Population and Development Review, 405-433.

Bueno, X., García Román, J. (2020). La fecundidad según la diferencia educativa y laboral entre cónyuges: ¿Tanto monta, monta tanto?. Perspectives Demogràphiques, 21.

Campillo Poza, I. (2010). Políticas de conciliación de la vida laboral y familiar en los regímenes de bienestar mediterráneos: los casos de Italia y España. Politica y sociedad, 47(1), 189-213.

Caselles, A., Ferrer, L., Martínez de Lejarza, I, Pla, R., Temre, R. (1999). Control del desempleo por Simulación. Valencia: Universitat de València.

Caselles, A. (1998). A tool for discovery by complex function fitting. In R. Trappl (Ed.), Cybernetics and systems research '98 (pp. 787-792). Vienna, Austria: Austrian Society for Cybernetic Studies.

Caselles, A. (2008). Modelización y simulación de sistemas complejos [Modeling and simulation of complex systems]. València, Spain: Universitat de València. Retrieved from http://www.uv.es/caselles

Castro-Martín, T. y T. Martín-García (2013), "Fecundidad bajo mínimos en España: pocos hijos, a edades tardías y por debajo de las aspiraciones reproductivas", In G. Esping-Andersen (Coord.), El déficit de la natalidad en Europa. La singularidad del caso español, Barcelona: Obra Social La Caixa: 48-88

Castro-Martín, T. \& Martín-García, T. (2016). La fecundidad en España: entre las más bajas del mundo y sin muchas perspectivas de recuperación. Panorama social, (23), 11-26.

Castro-Martín, T., Martín-García, T., Cordero, J. \& Seiz, M. (2018). El desafío de la baja fecundidad en España. In Informe España 2018 (pp. 165-232). Cátedra José María Martín Patino de la Cultura del Encuentro.

Castro-Martín, T., Martín-García, T., Cordero, J., Seiz, M. (2020). La muy baja fecundidad en España: la brecha entre deseos y realidades reproductivas. Dossier Economistas sin Fronteras, 36, 8-13.

Castro-Martín, T. \& M. Seiz (2014), "La transformación de las familias en España desde una perspectiva sociodemográfica", VII Informe sobre exclusión y desarrollo social en España, Documento de Trabajo 1.1, Madrid, Fundación Foessa

D'Addio, A. C., \& d'Ercole, M. M. (2005). Trends and determinants of fertility rates: The role of policies (Vol. 27). France: OECD Social, Employment and Migration Working Papers, OECD Publishing.

Del Rey Poveda, A \& Ortega Osona, J. (2011). La reproducción de la población en las provincias españolas (19752005). Análisis a través del reemplazo de nacimientos. Revista Internacional de Sociología, 69(1), 91-120.

Devolder, D., \& Bueno, X. (2011). Interacciones entre fecundidad y migración. Un estudio de las personas nacidas en el extranjero y residentes en Cataluña en 2007. Documents d'anàlisi geogràfica, 57(3), 441-467.

Díaz Gandasegui, V., Díaz-Gorfinkiel, M., \& Elizalde-San Miguel, B. (2017). Caring for children under three years in two different models of welfare states: The cases of Spain and Norway. Journal of Comparative Family Studies, 48(2), 157-175.

Djidjeli, K., Price, W. G., Temarel, P., \& Twizell, E. H. (1998). Partially implicit schemes for the numerical solutions of some non-linear differential equations. Applied Mathematics and Computation, 96, 177-207.

Eydal, G. B., \& Rostgaard, T. (2011). Day care schemes and cash for care at home. In Norden (Ed.) Parental leave, childcare and gender equality in the Nordic Countries. http://ffdd.ru/activ ity/attac h/infor matio n/182/paren tal_leave child care_and_gender_equal ity_in_the_nordi c_count ries.pdf 
Elizalde-San Miguel, B; Díaz Gandasegui, V. \& Díaz Gorfinkiel, M. (2019). Is Involved Fatherhood Possible? Structural Elements Influencing the Exercise of Paternity in Spain and Norway. Journal of Family Issues, doi:10.1007.s11205-018-1920-5

Elizalde-San Miguel, B; Díaz Gandasegui, V. y Sanz, M. T. (2019): Family Policy Index: A tool for policy makers to increase the efectiveness of family policies. Social Indicators Research, 142(1), 387-409. doi:10.1007.s11205018-1920-5

Esping-Andersen, G. (1990). The Three Worlds of Welfare Capitalism. Oxford: Polity Press.

Ferrera, M. (1996). The Southern model of welfare in Social Europe. Journal of European Social Policy, 20(4), 283-300

Gauthier, A. H. (2013). Family policy and fertility: Do policies make a difference? In A. Buchanan \& A. Rotkirch (Eds.), Fertility rates and population decline (pp. 269-287). London, UK: Palgrave Macmillan.

Gauthier, A. H., \& Philipov, D. (2008). Can policies enhance fertility in Europe? (pp. 1-16). Vienna, Austria: Yearbook of population research

Gietel-Basten, S., \& Sobotka, T. (2020). Uncertain population futures: Critical reflections on the IHME Scenarios of future fertility, mortality, migration and population trends from 2017 to 2100. https://doi.org/10.31235/osf.io/5syef.

Gornick, J. C., \& Meyers, M. K. (2008). Creating gender egalitarian societies: An agenda for reform. Politics \& Society, 36(3), 313-349.

Hegewisch, A., \& Gornick, J. (2010). The impact of work-family policies on women's employment: A review of research from OECD countries. Community, Work and Family, 14(2), 119-138. doi:10.1080/13668803.2011.571395

Hoem, J. M. (2008). The impact of public policies on European fertility. Demographic Research, 19, 249-260. doi:10.4054/DemRes.2008.19.10

Kalwij, A. (2010). The impact of family policy expenditure on fertility in western Europe. Demography, 47(2), 503-519.

Kammerman, S. B. \& Kahn, A. J. ( 1994). Family policy and the under threes: money, services and time in a policy package. International Social Security Review, 47(3-4), 31-43.

Korpi, W. (2000). Faces of inequality: Gender, class and patters of inequalities in different types of welfare States. Social Politics: International Studies in Gender, State and Society, 7(2), 127-191. doi:10.1093/sp/7.2.127

Kvande, E. (2009). Work-Life balance for fathers in globalized knowledge work. Some insights from the Norwegian context. Gender, Work \& Organization, 16(1), 58-72. doi:10.1111/j.1468-0432.2008.00430.x

Lappegård, T. (2010). Family policies and fertility in Norway. European Journal of Population/Revue européenne de Démographie, 26(1), 99-116. doi:10.1007/s10680-009-9190-1

León, M., \& Pavolini, E. (2014). Social investment or back to 'Familism': The impact of the economic crisis on family and care policies in Italy and Spain. South European Society and Politics, 19(3), 353-369

Luci-Greulich, A., \& Thévenon, O. (2013). The impact of family policies on fertility trends in developed countries. European Journal of Population/Revue européenne de Démographie, 29(4), 387-416. doi:10.1007/s10680-0139295-4

McDonald, P. (2001). Work-family policies are the right approach to the prevention of very low fertility. People and Place, 9(3), 17.

Micó, J.C., Caselles, A., Soler, D., Sanz, T., Martínez, E. (2008). A Side-by-Side Single Sex Age-Structured 
Human Population Dynamic Model: Exact Solution and Model Validation. The Journal of Mathematical Sociology, 32(4), 285-321. doi: 10.1080/00222500802352758.

Micó, J.C.; Soler, D.; Sanz, M.T.; Caselles, A.; Amigó, S. (2019). Optimizing the demographic rates to control the dependency ratio through a genetic algorithm. In Company, R., Cortés, J.C., Jódar, L. and López-Navaroo, E. (Eds.), Mathematical modelling in engineering \& human behaviour 2019 (pp. 185-192). Valencia, Spain: Universitat Politècnica de València.

OECD. (2017). The pursuit of Gender Equality: an Unphill Battle. Paris: OECD Publishing.

Rindfuss, R. R., Guilkey, D. K., Morgan, S. P., \& Kravdal, Ø. (2010). Child-care availability and fertility in Norway. Population and Development Review, 36(4), 725-748.

Rønsen, M. (2004). Fertility and family policy in Norway - A reflection on trends and possible connections. Demographic Research, 10, 265-286. doi:10.4054/DemRes.2004.10.10

Rønsen, M., \& Skrede, K. (2010). Can public policies sustain fertility in the Nordic countries?: Lessons from the past and questions for the future. Demographic research, 22, 321-346.

Rostgaard, T. (2014). Family policies in Scandinavia. Berlin, Germany: Friedrich Ebert Stiftung.

Salles, A., Rossier, C., \& Brachet, S. (2010). Understanding the long term effects of family policies on fertility: The diffusion of different family models in France and Germany. Demographic research, 22, 1057-1096.

Sanz, M. T; Díaz Gandasegui, V. \& Elizalde-San Miguel, B. (2019): Sense and sensibility: using a model to examine the relationship between public pre-school places and fertility. The Journal of Mathematical Sociology, On-line first. https://doi.org/10.1080/0022250X.2019.1583226.

Tobío, C. and Fernandez-Cordón, J. A. (2005). Conciliar las responsabilidades familiares y laborales: políticas y prácticas sociales (V.2). Madrid: Fundación Alternativas.

Sobotka, T., Beaujouan, E. (2014). Two is Best? The Persistence of a Two-Child Family Ideal in Europe. Population and Development Review, 40(3), 391-419.

Thévenon, O. (2010). Fertility in OECD countries: An assessment of macro-level trends and policy responses (Work Package, 2). REPRO Reproductive Decision-Making in a Macro-Micro Perspective. Vienna Institute of Demography, Vienna, Austria.

Thévenon, O. (2011). Family policies in OECD countries: A comparative analysis. Population and Development Review, 37(1), 57-87.

Thévenon, O., \& Gauthier, A. H. (2011). Family policies in developed countries: A 'fertility-booster' with sideeffects. Community, Work \& Family, 14(2), 197-216. doi:10.1080/13668803.2011.571400

Vollset S. E., et al, (2020). Fertility, mortality, migration, and population scenarios for 195 countries and territories from 2017 to 2100: a forecasting analysis for the Global Burden of Disease Study. The Lancet, 396(10258), 1258-1306. https://doi.org/10.1016/S0140-6736(20)30677-2. 